\title{
Thermodynamic Assessment of the Scandium-Gold Binary System
}

\author{
D. Moustaine and K. Mahdouk
}

Laboratory of Thermodynamics and Energetics (L.T.E.), Faculty of Science, Ibn Zohr University, B.P. 8106, Agadir, Morocco

\begin{abstract}
The phase diagram and thermodynamic properties of the Sc-Au system were carried out by means of the CALPHAD (calculation of phase diagrams) method through Thermo-Calc software package on the basis of the experimental data of phase equilibria and thermodynamic proprieties from the published literature data. The excess Gibbs energies functions of the solution phases including liquid, face-centered cubic fcc_A1, body-centered hexagonal close-packed hcp_3 and cubic bcc_A2, modeled with Redlich-Kister polynomials functions while all intermetallic compounds have been treated as stoichiometric compounds. The thermodynamic parameters describing various phases in the Sc-Au binary system were finally obtained, and a good agreement is achieved between the calculated results and the reported experimental data.
\end{abstract}

Key words: Phase diagram, thermodynamic assessment, CALPHAD method, thermodynamic modeling.

\section{Greek Letters}

$\begin{array}{ll}R & \text { gas constant } \\ T & \text { temperature } \\ x_{i} & \text { the mole fraction of component } i\end{array}$

\section{Introduction}

Sc-based alloys have been considered to be a new generation of high-performance alloy structural materials for aerospace, ships and weapons [1] and Sc addition on wrought alloys has positive effects on weldability and welding properties [2]. With the addition of a small amount of scandium, the tensile strength, elongation and hardness, as well as the corrosion and heat resistance of aluminum alloys can be significantly improved [3]. The phase equilibria in the Sc-based alloys systems are of importance for design of new Sc-based alloys.

Hence, the purpose of the present work is to assess the Sc-Au binary system for which the experimental phase diagram was reexamined by Palenzona et al. [4] and to develop a precise thermodynamic description by means of the CALPHAD (calculation of phase

Corresponding author: D. Moustaine, Ph.D., research field: materials science. diagram) technique described and presented by Refs. $[5,6]$ and successfully applied in various computer programs in order to give a more complete and consistent description of the phases existing in the studied system and their stability. The thermodynamic optimization of the Sc-Au system is part of a research program, actually carried out in our laboratory, and it focuses on the study of the interaction between rare earth elements and the noble metals.

\section{Review of Experimental Data}

Rider et al. [7], using X-ray powder diffraction methods, found that the addition of scandium to gold gives rise to an extended solid solution range up to 8.8 at. \% Sc at 1,313 K which is the eutectic temperature. The effect of the addition of gold on scandium has not been investigated due to some experimental difficulties that were encountered in the scandium rich side of the diagram owing to the reactivity of the alloys and to the contamination of the samples by the container material (Mo); this side of the diagram 0 to 20 at. \% Au has not been investigated. The melting points and transformation temperatures of scandium and gold were taken from Refs. [8, 9] respectively. 
Moffatt [10] reported the existence of the $\beta \mathrm{Sc} \leftrightarrow \alpha \mathrm{Sc}$ + liq metatectic reaction which occurs at $1,607 \mathrm{~K}$.

Based on differential thermal analysis, metallographic analysis, X-ray diffraction and electron microscopy, Palenzona et al. [4] investigated the first version of Sc-Au phase diagram in the range 20 to 90 at. \% Au, even if many intermediate compounds have been found and characterized by Okamoto and Massalski [11]. A total of six intermediate phases have been found. Three of them have been confirmed: $\mathrm{ScAu}[12,13], \mathrm{ScAu}_{2}$ and $\mathrm{ScAu}_{4}$ [13], while $\mathrm{Sc}_{3.5} \mathrm{Au}$, $\mathrm{Sc}_{2} \mathrm{Au}$ and $\mathrm{ScAu}_{3}$ have been found for the first time in this investigation. The $\mathrm{ScAu}$ and $\mathrm{ScAu}_{2}$ phases are melt congruently and $\mathrm{Sc}_{3.5} \mathrm{Au}, \mathrm{Sc}_{2} \mathrm{Au}, \mathrm{ScAu}_{3}$, and $\mathrm{ScAu}_{4}$ are formed peritectically. Later, Okamoto [14] published a reevaluated $\mathrm{Sc}-\mathrm{Au}$ phase diagram in which the $\mathrm{Sc}_{3.5} \mathrm{Au}$ phase adapted to $\mathrm{Sc}_{7} \mathrm{Au}_{2}$ formula. The existence of $\mathrm{Sc}_{2} \mathrm{Au}$ compound was predicted by Aldred [12] but no crystallographic data were given. Palenzona et al. [4], following the classification made in the work of Flahaut and Thévet [15], attributed its structure to the anti $\mathrm{PbCl}_{2}$-type, rather than to the $\mathrm{Co}_{2} \mathrm{Si}$-type which is reported by Renouf [16]. In the range 50 to 65 at. $\% \mathrm{Au}$ the thermal effects due to the eutectic at $1,798 \mathrm{~K}$ are always followed by a second effect at $1,783 \mathrm{~K}$ which [4] were not able to explain. This behaviour, however, seems not to be unusual since it has been already observed in systems like La-Ag, Nd-Ag [9], Pr-Au [17]. Also, Palenzona et al. [4] confirmed that the maximum solid solubility value, at the eutectic temperature reported by Ref. [7], is close to 9.0 at. \% Sc. and measured the invariants reactions temperatures and compositions of equilibrium phases, which are summarized in Table 1.

The crystal structures of the various phases have been reported by several investigators [4, 11-13, 16, 18 , 19] and the known structure data for the intermetallic compounds are summarized in Table 2.

The first calorimetric measurements were carried out at $1,379 \mathrm{~K}$ by Kleppa and Topor [24] who measured the enthalpies of mixing of the liquid phase. Later, Fitzner et al. [22], by means of high temperature

Table 1 Comparison between the calculated and experimental results $[4,10]$ in the Sc-Au system.

\begin{tabular}{|c|c|c|c|c|c|c|c|c|c|}
\hline \multirow{2}{*}{$\frac{\text { Reaction }}{\mathrm{Liq} \leftrightarrow \mathrm{Sc}_{7} \mathrm{Au}_{2}+\alpha \mathrm{Sc}}$} & \multicolumn{3}{|c|}{$\begin{array}{l}\text { Compositions from current work } \\
\text { (at. \% } \mathrm{Au})\end{array}$} & \multirow{2}{*}{$\begin{array}{l}\mathrm{T}(\mathrm{K}) \\
1,388\end{array}$} & \multicolumn{3}{|c|}{$\begin{array}{l}\text { Compositions from literature data } \\
(\text { at. } \% \mathrm{Au})\end{array}$} & \multirow{2}{*}{$\begin{array}{l}T(\mathrm{~K}) \\
1,388\end{array}$} & \multirow{2}{*}{$\begin{array}{l}\text { Ref. } \\
{[4]}\end{array}$} \\
\hline & 16.3 & 22.2 & 0.03 & & 18 & 22.2 & - & & \\
\hline $\mathrm{Liq}+\mathrm{Sc}_{2} \mathrm{Au} \leftrightarrow \mathrm{Sc}_{7} \mathrm{Au}_{2}$ & 19.3 & 33.3 & 22.2 & 1,407 & 19 & 33.3 & 22.2 & 1,408 & {$[4]$} \\
\hline $\mathrm{Liq}+\mathrm{ScAu} \leftrightarrow \mathrm{Sc}_{2} \mathrm{Au}$ & 31.8 & 50 & 33.3 & 1,548 & 29 & 50 & 33.3 & 1,548 & [4] \\
\hline $\mathrm{Liq} \leftrightarrow \mathrm{ScAu}$ & 50 & & & 1,972 & 50 & & & 1,973 & {$[4]$} \\
\hline $\mathrm{Liq} \leftrightarrow \mathrm{ScAu}+\mathrm{ScAu}_{2}$ & 59.4 & 50 & 66.7 & 1,801 & 61 & 50.0 & 66.7 & 1,798 & [4] \\
\hline $\mathrm{Liq} \leftrightarrow \mathrm{ScAu}_{2}$ & 66.7 & & & 1,886 & 66.7 & & & 1,888 & [4] \\
\hline $\mathrm{Liq}+\mathrm{ScAu} \leftrightarrow \mathrm{ScAu}_{3}$ & 78.6 & 66.7 & 75 & 1,579 & 77 & 66.7 & 75 & 1,578 & {$[4]$} \\
\hline $\mathrm{Liq}+\mathrm{ScAu}_{3} \leftrightarrow \mathrm{ScAu}_{4}$ & 82 & 75 & 80 & 1,498 & 83 & 75 & 80 & 1,498 & {$[4]$} \\
\hline$(\beta S C) \leftrightarrow(\alpha \mathrm{SC})+$ liq & 2 & 1.6 & 8.9 & 1,607 & - & - & 7 & 1,607 & [10] \\
\hline
\end{tabular}

Table 2 The crystal structures of the various phases in the Sc-Au system.

\begin{tabular}{lllllll}
\hline Phase & $\begin{array}{l}\text { Composition, } \\
\text { at. } \% \mathrm{Au}\end{array}$ & $\begin{array}{l}\text { Pearson } \\
\text { symbol }\end{array}$ & Space group & $\begin{array}{l}\text { Symbol used in thermo-calc } \\
\text { data file }\end{array}$ & Prototype & Ref. \\
\hline $\mathrm{Au}$ & 91.2 & $\mathrm{cF} 4$ & $m 3 m$ & $\mathrm{FCC} \_\mathrm{A} 1$ & $\mathrm{Cu}$ & {$[18]$} \\
$\alpha \mathrm{Sc}$ & 0 & $\mathrm{hp} 2$ & $P 63 / m m c$ & $\mathrm{HCP} \mathrm{A} 3$ & $\mathrm{Mg}$ & {$[19]$} \\
$\beta \mathrm{Sc}$ & 0 & $\mathrm{hp} 2$ & $P 63 / m m c$ & $\mathrm{BBC}{ }_{-} \mathrm{A} 2$ & $\mathrm{~W}$ & {$[19]$} \\
$\mathrm{Sc}_{7} \mathrm{Au}_{2}$ & 22.2 & $\mathrm{oI} 142$ & $I m m m$ & $\mathrm{Sc}_{7} \mathrm{Au}_{2}$ & $\mathrm{Hf}_{54} \mathrm{Os}_{17}$ & {$[17]$} \\
$\mathrm{Sc}_{2} \mathrm{Au}$ & 33.3 & $\mathrm{oP} 12$ & $P m n a$ & $\mathrm{Sc}_{2} \mathrm{Au}$ & $\mathrm{PbCl}_{2}$ & {$[20]$} \\
$\mathrm{ScAu}_{2}$ & 66.7 & $\mathrm{tI} 6$ & $I 4 / m m m$ & $\mathrm{ScAu}_{2}$ & $\mathrm{MoSi}_{2}$ & {$[4,11,13]$} \\
$\mathrm{ScAu}_{3}$ & 75 & $\mathrm{op} 8$ & $P m n a$ & $\mathrm{ScAu}_{3}$ & $\mathrm{TiCu}_{3}$ & {$[4]$} \\
$\mathrm{ScAu}_{4}$ & 80 & $\mathrm{tI} 10$ & $I 4 / m$ & $\mathrm{ScAu}_{4}$ & $\mathrm{MoNi}_{4}$ & {$[4,11,13,17]$} \\
\hline
\end{tabular}


Table 3 Comparison between measured and optimized enthalpies and entropies of formation of the Sc-Au intermetallic compounds.

\begin{tabular}{|c|c|c|c|c|c|}
\hline $\begin{array}{l}\text { Intermetallic } \\
\text { compounds }\end{array}$ & $\begin{array}{l}\text { Enthalpy of formation } \\
\Delta \mathrm{H}_{\mathrm{f}}(\mathrm{kJ} / \mathrm{mol} \text {.at. })\end{array}$ & Technique used & $T(\mathrm{~K})$ & $\begin{array}{l}\text { Entropy of formation } \\
\Delta \mathrm{S}_{\mathrm{f}}(\mathrm{J} / \mathrm{mol} \cdot \mathrm{K})\end{array}$ & Ref. \\
\hline \multirow{2}{*}{$\mathrm{Sc}_{7} \mathrm{Au}_{2}$} & -53.00 & Optimization & 298.15 & -12.5 & {$[21]$} \\
\hline & -55.55 & Optimization & 298.15 & -13.1 & This work \\
\hline \multirow{2}{*}{$\mathrm{Sc}_{2} \mathrm{Au}$} & -63.00 & Optimization & 298.15 & -7.72 & {$[21]$} \\
\hline & -73.59 & Optimization & 298.15 & -13.5 & This work \\
\hline \multirow{3}{*}{$\mathrm{ScAu}$} & -73.1 & Optimization & 298.15 & -3.70 & {$[21]$} \\
\hline & $-76.1 \pm 3$ & Calorimetry & $1,473 \pm 2$ & - & {$[22]$} \\
\hline & -78.39 & Optimization & 298.15 & -3.4 & This work \\
\hline \multirow{3}{*}{$\mathrm{ScAu}_{2}$} & -66.98 & Optimization & 298.15 & -0.54 & {$[21]$} \\
\hline & $-83.2 \pm 1.8$ & Calorimetry & 1,372 & - & {$[23]$} \\
\hline & -82.23 & Optimization & 298.15 & -4 & This work \\
\hline \multirow{2}{*}{$\mathrm{ScAu}_{3}$} & -60.00 & Optimization & 298.15 & -3.25 & {$[21]$} \\
\hline & -69.93 & Optimization & 298.15 & -2.80 & This work \\
\hline \multirow{3}{*}{$\mathrm{ScAu}_{4}$} & -54.00 & Optimization & 298.15 & -4.65 & {$[21]$} \\
\hline & $-57.3 \pm 1.5$ & Calorimetry & 1,372 & - & {$[23]$} \\
\hline & -58.13 & Optimization & 298.15 & -1.48 & This work \\
\hline
\end{tabular}

direct synthesis calorimetric at $1,473 \mathrm{~K}$, measured the enthalpy of formation of the ScAu phase as well as the enthalpy of mixing of the liquid phase at 50\% Au. later on, in another experiment conducted by Meschel and Kleppa [23], they determined the enthalpies of formation for the tow compounds $\mathrm{ScAu}_{4}$ and $\mathrm{ScAu}_{2}$ at $1,372 \mathrm{~K}$. In Table 3, we summarize the different enthalpies of formation values obtained by various authors and the ones calculated in the current work.

\section{Thermodynamic Models}

\subsection{Pure Elements}

The Gibbs energy function

$G_{\mathrm{i}}^{\Phi}(T)={ }^{0} G_{\mathrm{i}}^{\Phi}-H_{\mathrm{i}}^{S E R}(29815 K)$ for the element $\mathrm{i}(\mathrm{i}=$ $\mathrm{Sc}, \mathrm{Au})$ in the phase $\Phi\left(\Phi=\right.$ Liquid, $\mathrm{HCP}_{-} \mathrm{A} 3$, FCC_A1 and BCC_A2) is described by an equation of the following form:

$$
G_{i}^{\Phi}(T)=a+b T+c T+d T^{2}+e T^{3}+f T^{7}+g T^{-1}+h T^{-9}
$$

where $H_{\mathrm{i}}^{S E R}(298.15 K)$ is the molar enthalpy of the element $\mathrm{i}$ at $298.15 \mathrm{~K}$ in its SER (standard element reference) state, HCP_A3 for Sc and FCC_A1 for Au.

In this work, the Gibbs energy functions are taken from the SGTE (Scientific Group Thermo Data Europe) compilation of Dinsdale [25].

\subsection{Solution Phases}

The solution phases (BCC_A2), (HCP_A3), (FCC_A1) and liquid were modelled as substitutional solutions according to the polynomial Redlich-Kister model [26]. The Gibbs energy of $1 \mathrm{~mol}$ of formula unit of phase $\Phi$ in the Sc-Au is expressed as the sum of the reference part ${ }^{r e f} G^{\Phi}$, the ideal part ${ }^{i d} G^{\Phi}$, and the excess part ${ }^{e x c} G^{\Phi}$ :

$$
\begin{gathered}
G_{m}^{\Phi}={ }^{r e f} G^{\Phi}+{ }^{i d} G^{\Phi}+{ }^{e x c} G^{\Phi} \\
{ }^{r e f} G^{\Phi}(T)=\left({ }^{0} G_{S c}^{\Phi}(T)-H_{\Phi}^{S E R}(29815 K)\right) X_{S c}+ \\
\left({ }^{0} G_{A u}^{\Phi}(T)-H_{A u}^{f c c_{-} A 1}(29815 K)\right) X_{A u} \\
{ }^{i d} G^{\Phi}=R T\left(X_{S c} \ln X_{S c}+X_{A u} \ln X_{A u}\right)
\end{gathered}
$$

The excess terms of all the solution phases were modelled by the Redlich-Kister [26] formula:

$$
{ }^{\operatorname{exc}}{ }_{G}^{\Phi}(T)=X_{S c} X_{A u}\left[\sum_{\mathrm{i}=0}^{n}{ }^{\mathrm{i}} L_{S c, A u}^{\Phi}(T)\left(X_{S c}-X_{A u}\right) \mathrm{i}\right]
$$

where $x_{\mathrm{Sc}}$ and $x_{\mathrm{Au}}$ are the mole fraction of elements Sc and Au respectively; $T$ is the temperature in Kelvin, $R$ is the gas constant, while ${ }^{\mathrm{i}} L_{S c, A u}^{\Phi}(T)$ is the interaction parameter between the elements $\mathrm{Sc}$ and $\mathrm{Au}$, to be evaluated in the present work. Its general form is: 


$$
{ }^{\mathrm{i}} L_{S c, A u}^{\Phi}(T)=a_{\mathrm{i}}+b_{1} T+c_{\mathrm{i}} T \ln T+d_{\mathrm{i}} T^{2}+e_{\mathrm{i}} T^{3}+f_{\mathrm{i}} T^{-1}
$$

Because of the lack of experimental measurements relative to the $C p$ values of the $\mathrm{Sc}-\mathrm{Au}$ phases, we have restricted the ${ }^{\mathrm{i}} L_{S c, A u}^{\Phi}(T)$ temperature dependence expression (Eq. (6)) to its two first terms, i.e.:

$$
{ }^{\mathrm{i}} L_{S c, A u}^{\Phi}(T)=a_{\mathrm{i}}+b_{\mathrm{i}} T
$$

where $a_{i}$ and $b_{i}$ are the coefficients to be optimized using the PARROT (thermo-calc software throughout) module [27]..

\subsection{Intermetallic Compounds}

The Gibbs energy of the stoichiometric compounds $\mathrm{ApBq}$ is expressed as follows:

$$
{ }^{0} G_{S c_{p} A u_{q}}=\frac{p}{p+q}{ }^{0} G_{S c}+\frac{q}{p+q}{ }^{0} G_{A u}+a+b T
$$

where ${ }^{0} G_{S c}$ and ${ }^{0} G_{A u}$ are the Gibbs energy of the pure elements $\mathrm{Sc}$ and $\mathrm{Au}$, respectively, $a$ and $b$ were evaluated in the current work based on the literature data.

\section{Assessment Procedure}

The optimization of the thermodynamic parameters was done using Parrot module of the thermo-calc software developed by Jansson [27] and Andersson et al. [28]. Its process includes choosing thermodynamic models for the Gibbs energy of the individual phases as previously described, the analysis of the all related experimental data available in the literature, and the computer-aided nonlinear for minimizing the square sum of the errors between the experimental data and the computed values. At the outset of the assessment, each piece of selected information was given a certain weight. The weights were changed systematically during the assessment, until most of the selected experimental data were accounted for within the claimed uncertainty limits. The optimization was carried out in steps. Firstly, the liquid phase was optimized as regular solution using the integral enthalpies of mixing of the liquid [22]. Secondly, the thermodynamic parameters for the intermetallic compounds were optimized based on the available experimental standard enthalpies of formation for the Sc-Au intermetallic compounds [22,23] and the phase boundaries information. Then, experimental data related to the invariant reactions [4] were added to the calculation. All the parameters were finally evaluated together to give the best thermodynamic description of the Sc-Au binary system.

\section{Results and Discussion}

The thermodynamic description of the Sc-Au system was performed in the present research using the PARROT module in the Thermo-Calc software [27] and taking into consideration all the relevant experimental results published by Palenzona et al. [4] and the thermodynamic proprieties available in the literature for the Sc-Au system, as discussed in the following sections. The thermodynamic parameters for all condensed phases in the Sc-Au binary system obtained in the present work are summarized in Table 4.

In Table 1 we give the invariant equilibria of the $\mathrm{Sc}-\mathrm{Au}$ system with their respective compositions and temperatures. Satisfactory agreement was obtained between the calculated results and experimental data reported by Refs. [4, 10]. The calculated phase diagram of Sc-Au system is displayed in Fig. 1.

In Fig. 2 we compared our calculated phase diagram with the experimental data established by Palenzona et al. [4]. We noted that there is a good agreement between the calculated and experimental data [4] with regard to the compositions and temperatures of phase boundaries and invariant reactions.

The calculated standard enthalpies of formation in the Sc-Au system compared with the experimental data determined by Fitzner and Kleppa [22] and by Meschel and Kleppa [23] are presented in Fig. 3. A remarkable agreement is seen between the experimental enthalpies of formation and those 
obtained by our calculations. However, when we compare our calculated values with the ones from the work of Ref. [21] we noted that there is a discrepancy between our calculated values and those from the work of Ref. [21] which reaches about 16 (kJ/mol.at.) concerning the $\mathrm{ScAu}_{2}$ phase seen in Table 4 and Fig. 3. It should be pointed out that $\mathrm{Xu}$ et al. [21] assess the Sc-Au binary system without taking in consideration the experimental data published by Ref. [23].
So as to check the reliability of our parameters, we calculated the phase diagram without the liquid phase as indicated by different researchers [29, 30] in Fig. 4. The result showed the following: the six intermetallic phases disappear at high temperatures, the fcc_A1 terminal solid solution is stable on the Au-side, and the bcc_A2 terminal solid solution is stable on the Sc-rich side; between these single phase domains the two phase domains (fcc_A1 + bcc_A2) are stable. This

Table 4 Optimized thermodynamic parameters of the Sc-Au system.

\begin{tabular}{|c|c|c|}
\hline Phase & Thermodynamic models & Parameters in SI \\
\hline Liquid & $(\mathrm{Sc}, \mathrm{Au})$ & $\begin{aligned}{ }^{0} L^{\text {Liquid }} & =-271,526.7+23.92 \times T \\
{ }^{1} L^{\text {Liquid }} & =-4,128-68.62 \times T \\
{ }^{2} L^{\text {Liquid }} & =58,574-58.02 \times \mathrm{T}\end{aligned}$ \\
\hline BCC_A2 & $(\mathrm{Sc}, \mathrm{Au})_{1}:(\mathrm{Va})_{3}$ & ${ }^{0} \mathrm{~L}^{\mathrm{Bcc}}-{ }^{\mathrm{A} 2}=-163474+15.94 * \mathrm{~T}$ \\
\hline $\mathrm{Sc}_{7} \mathrm{Au}_{2}$ & $(\mathrm{Sc})_{0.777}:(\mathrm{Au})_{0.222}$ & $\begin{array}{l}\mathrm{G}_{\mathrm{ScAu}}^{\mathrm{Sc}_{2} \mathrm{Au}_{2}}-0.777 * \mathrm{H}_{\mathrm{Sc}}^{\mathrm{HCP} \_}{ }^{\mathrm{A} 3}-0.222 * \mathrm{H}_{\mathrm{Au}}^{\mathrm{FCC} \_\mathrm{A} 1}= \\
0.222 \mathrm{G}_{\mathrm{Au}}^{\mathrm{FCC} \_\mathrm{Al}}+0.77 \mathrm{G}_{\mathrm{Sc}}^{\mathrm{HCP} \_\mathrm{A} 3}-5555713.1 * \mathrm{~T}\end{array}$ \\
\hline $\mathrm{Sc}_{2} \mathrm{Au}$ & $(\mathrm{Sc})_{0.667}:(\mathrm{Au})_{0.333}$ & $\begin{array}{l}\mathrm{G}_{\mathrm{ScAu}}^{\mathrm{Sc} \mathrm{Su}_{2}}-0.667 * \mathrm{H}_{\mathrm{Sc}}^{\mathrm{HCP} \_}{ }^{\mathrm{A} 3}-0.333 * \mathrm{H}_{\mathrm{Au}}^{\mathrm{FCC} \_\mathrm{A} 1} \\
={ }^{0.333 \mathrm{G}_{\mathrm{Au}}^{\mathrm{FCC}}{ }^{\mathrm{FCl}}+0.66 \mathrm{~T}_{\mathrm{Sc}}^{\mathrm{HCP}}{ }^{\mathrm{A} 3}-73596+13.5 * \mathrm{~T}}\end{array}$ \\
\hline $\mathrm{ScAu}$ & $(\mathrm{Sc})_{0.500}:(\mathrm{Au})_{0.500}$ & $\begin{array}{l}\mathrm{G}_{\mathrm{Sc}: \mathrm{Au}}^{\mathrm{ScAu}}-0.5 * \mathrm{H}_{\mathrm{Sc}}^{\mathrm{HCP}} \mathrm{H}^{\mathrm{A} 3}-0.5 * \mathrm{H}_{\mathrm{Au}}^{\mathrm{FCC}{ }^{\mathrm{Al}}=}= \\
0.5 * \mathrm{G}_{\mathrm{Sc}}^{\mathrm{HC}}{ }^{\mathrm{HC} 3}+0.5 * \mathrm{G}_{\mathrm{Au}}^{\mathrm{FCC}}{ }^{\mathrm{Al}}-78399+3.47 * \mathrm{~T}\end{array}$ \\
\hline $\mathrm{ScAu}_{2}$ & $(\mathrm{Sc})_{0.333}:(\mathrm{Au})_{0.667}$ & $\begin{array}{l}\mathrm{G}_{\mathrm{ScAu}}^{\mathrm{Sc} \mathrm{Au}_{2}}-0.333 * \mathrm{H}_{\mathrm{Sc}}^{\mathrm{HCP}{ }_{-} \mathrm{A} 3}-0.667 * \mathrm{H}_{\mathrm{Au}}^{\mathrm{FCC} \_\mathrm{A} 1}= \\
0.667 \mathrm{~T}_{\mathrm{Au}}^{\mathrm{FCC} \_\mathrm{Al}}+0.333 \mathrm{G}_{\mathrm{Sc}}^{\mathrm{HCP} \_}{ }^{\mathrm{A} 3}-82234+4 * \mathrm{~T}\end{array}$ \\
\hline $\mathrm{ScAu}_{3}$ & $(\mathrm{Sc})_{0.250}:(\mathrm{Au})_{0.750}$ & 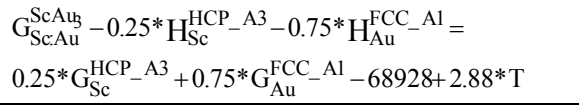 \\
\hline $\mathrm{ScAu}_{4}$ & $(\mathrm{Sc})_{0.200}:(\mathrm{Au})_{0.800}$ & 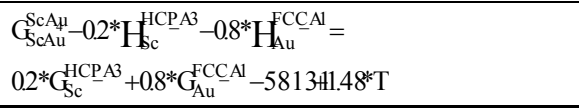 \\
\hline
\end{tabular}

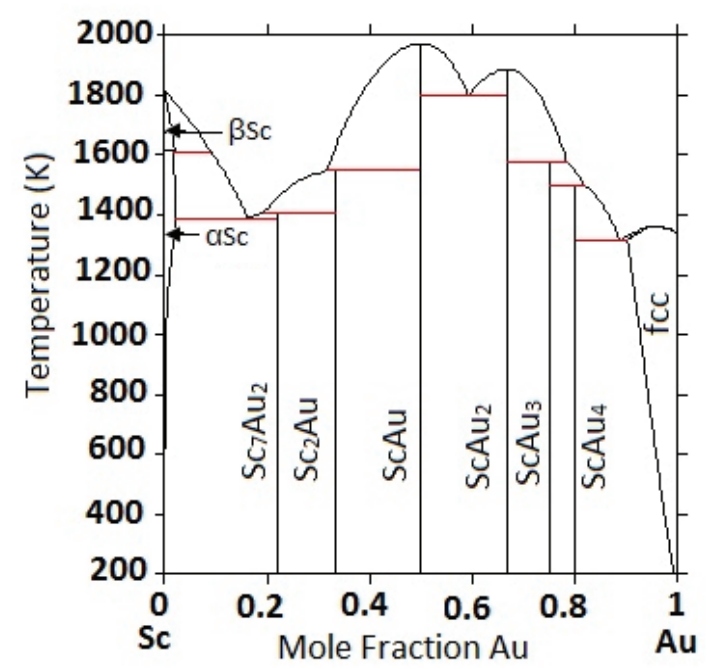

Fig. 1 The Sc-Au phase diagram calculated by the present thermodynamic description in this work. 


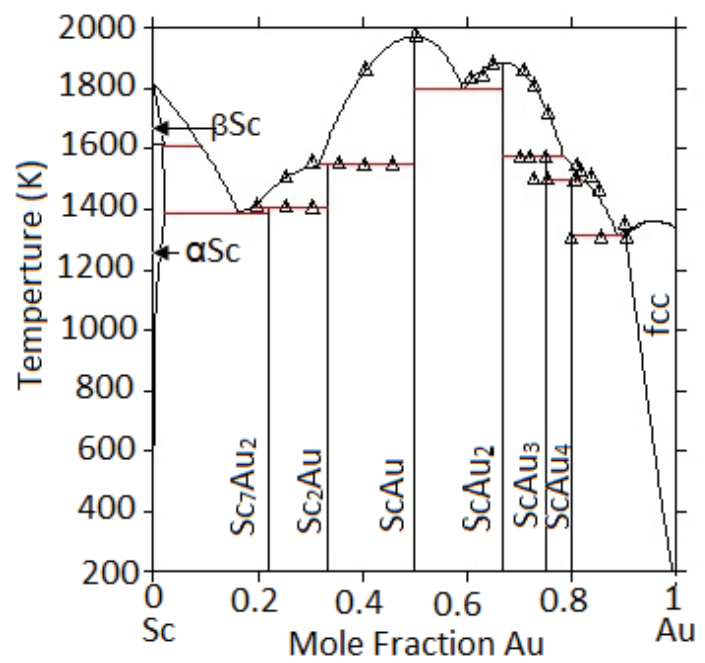

Fig. 2 Calculated phase diagram of the Sc-Au system compared with the experimental data [4].

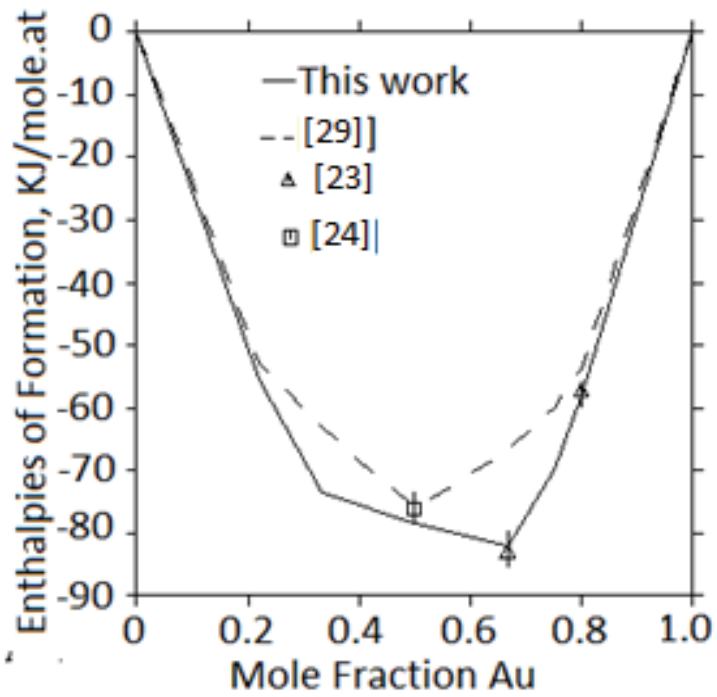

Fig. 3 Calculated and measured enthalpies of formation of the intermetallic compounds.

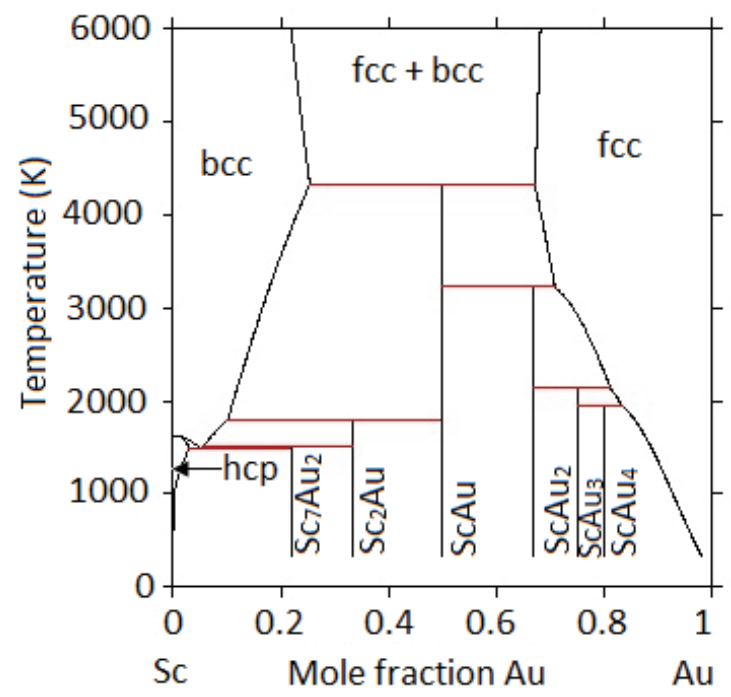

Fig. 4 Calculated Sc-Au phase diagram when the liquid phase is suspended. 
extra criterion provides a better test of the reliability of the Gibbs energy descriptions for extrapolation.

The calculated Gibbs energy of mixing the liquid phase at different temperatures is shown in Fig. 5. We noticed that this function becomes more negative when the temperature increases. This is due to configurational entropy effects. In addition, no reversed miscibility gap in the liquid phase was detected until 4,000 K.

As shown in Fig. 6, the calculated values of the enthalpies of mixing the liquid phase are compared with the calorimetric results by Kleppa and Torpor [24]. A good agreement was observed.

Fig. 7 presents the change of the enthalpy of mixing the liquid phase measured by several investigators [22, $24,31]$ using direct synthesis calorimetry at high temperature for the binary systems Sc-X, where $\mathrm{X}=$ $\mathrm{Cu}, \mathrm{Ag}$ and $\mathrm{Au}$ and calculated by several authors [32, 33] using thermodynamic optimization and semiempirical model of Miedema respectively. As expected, the liquid enthalpy of mixing the Sc-X liquid alloys becomes more negative in the following order: $\mathrm{Cu}, \mathrm{Ag}$ and $\mathrm{Au}$. On the other hand, the maximum ordering composition in the liquid solution is located in the vicinity of the molar fraction $x=0.6$ of the noble metals.

Fig. 8 shows the experimental standard enthalpies of formation of $\mathrm{Sc}-\mathrm{X}(\mathrm{X}=\mathrm{Cu}, \mathrm{Ag}$ and $\mathrm{Au})$ intermetallic compounds measured by Refs. [22, 23, $31,32,34]$, using direct reaction calorimetry at high temperature, together with the calculated values from the current work and other optimization studies from Refs. [34, 36]. We noted that the enthalpies of formation increase with the atomic number of the $\mathrm{X}$ element $(\mathrm{X}=\mathrm{Cu}, \mathrm{Ag}$ and $\mathrm{Au})$. The very strong interaction of Sc with the noble metals is noted for the late element of this group. We also observed, that the shape of the enthalpies of formation versus composition presents a pronounced shift toward the $x$ $=0.67$ composition for the Sc-Au alloys.

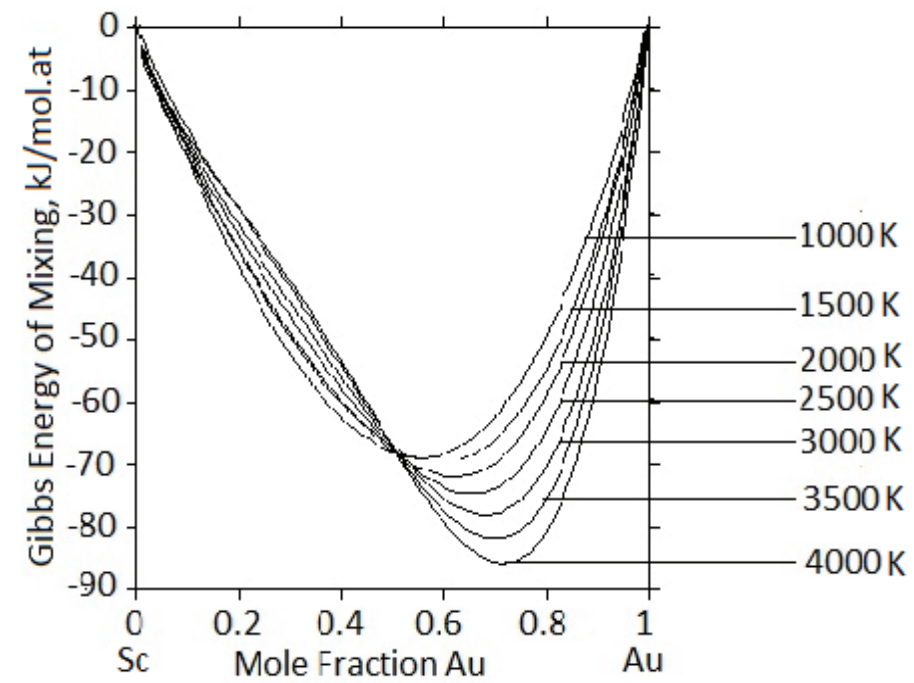

Fig. 5 Gibbs energy of mixing of the liquid phase at different temperature. The reference states are Sc and Au liquids. 


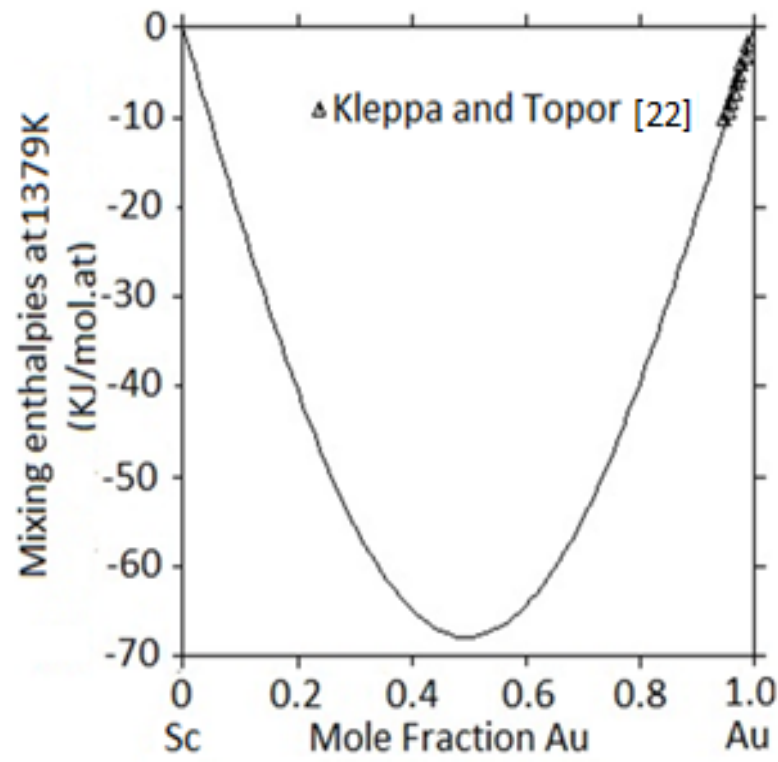

Fig. 6 Calculated enthalpies of mixing of the liquid phase compared with the measured values at 1,379 K by Kleppa and Topor [24].

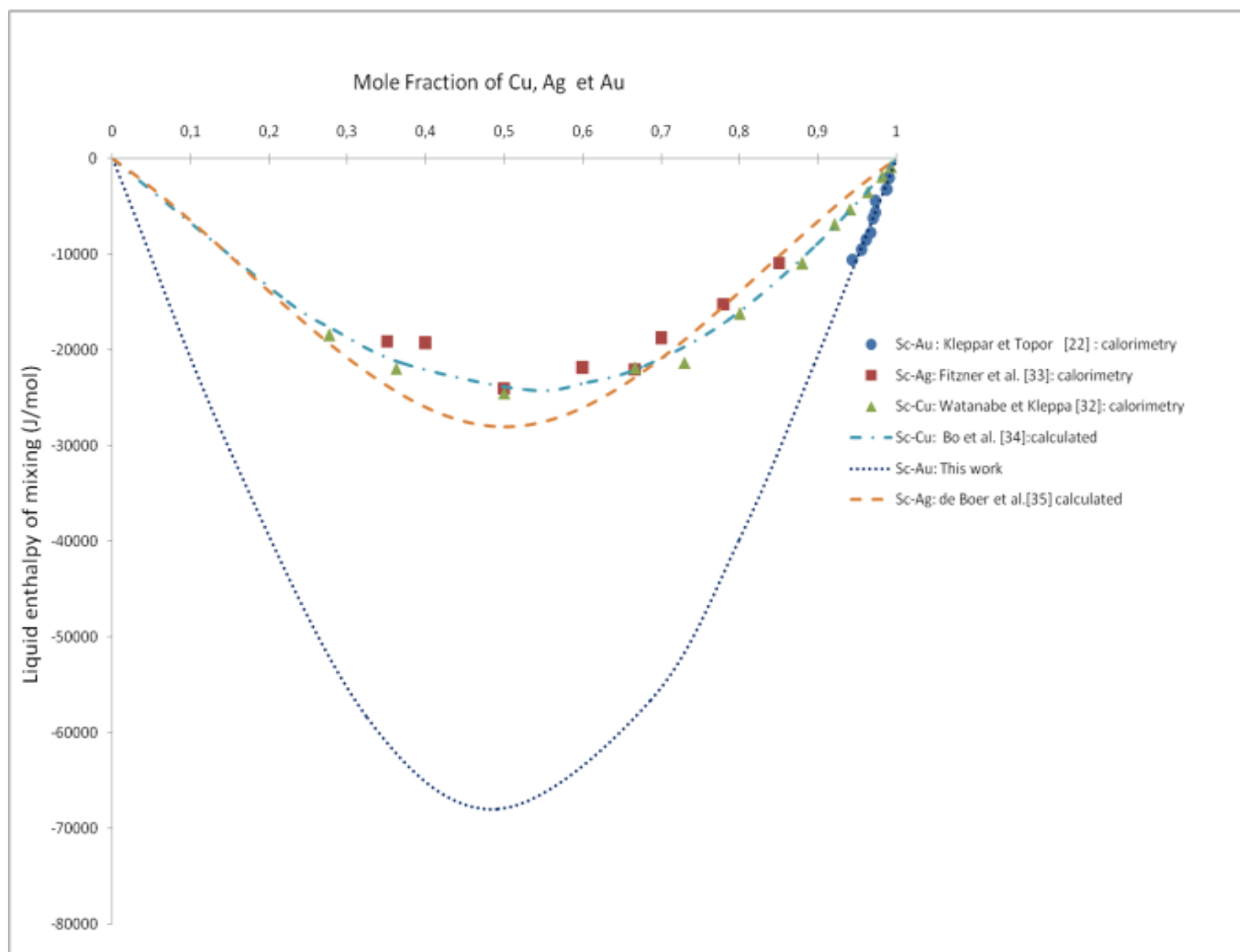

Fig. 7 Calculated liquid enthalpies of mixing in the binary systems Sc-X, where $\mathrm{X}=\mathrm{Cu}, \mathrm{Ag}$ and $\mathrm{Au}$, compared with the results in the literature. 


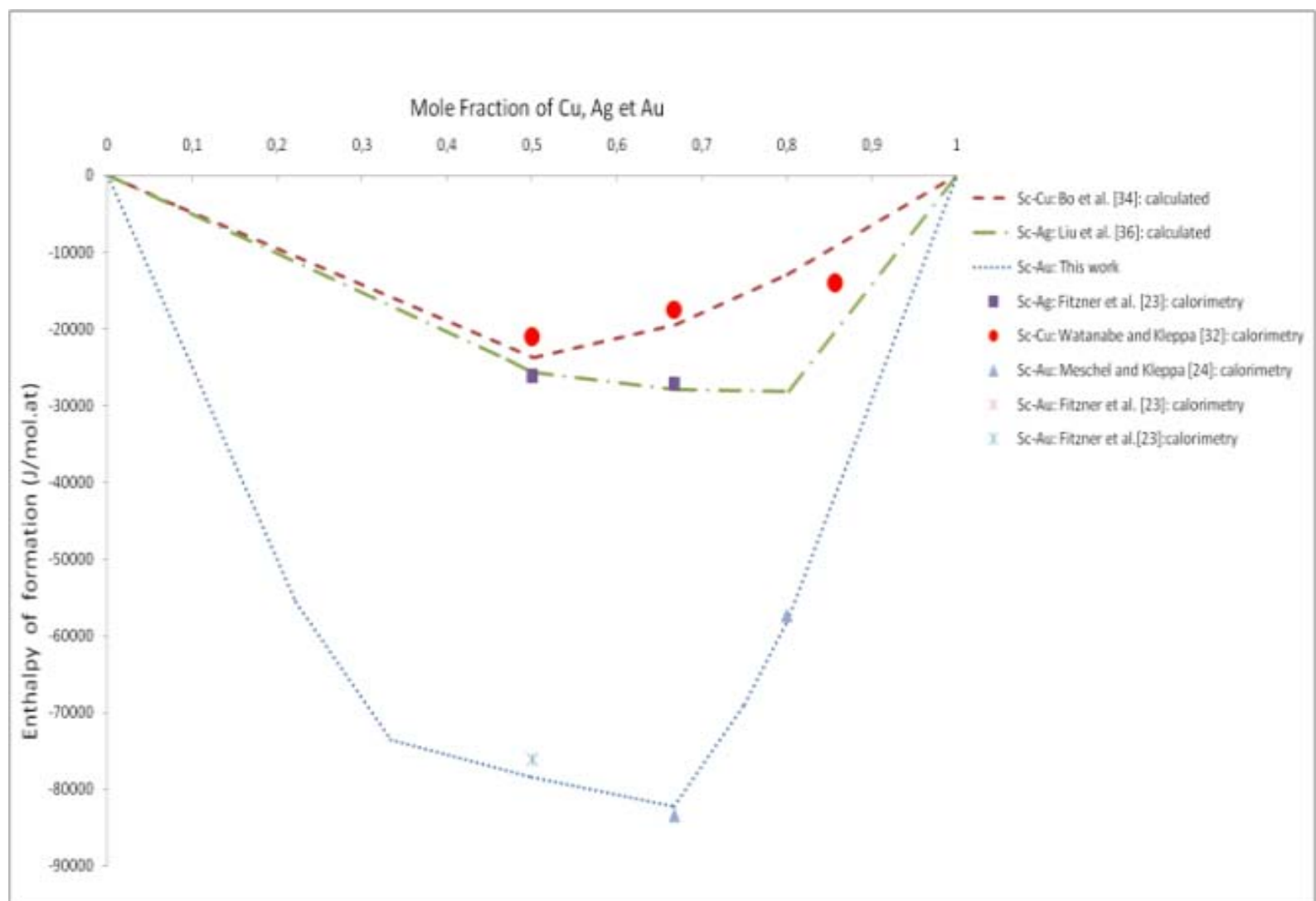

Fig. 8 Calculated standard enthalpies of formation of Sc-X (X = Cu, Ag and Au) intermetallic compounds compared with data from literature.

\section{Conclusions}

By taking into consideration all the experimental data including the phase equilibria and thermodynamic properties available in literature, we critically assessed the phase diagrams in the Sc-Au binary system on the basis of the optimized thermodynamic parameters. Addedly, the calculated phase equilibria and the thermodynamic properties, such enthalpies of mixing the liquid phase, standard enthalpies of formation of the Sc-Au intermediate phases and Gibbs free energies of mixing of the liquid were confronted to the available data from literature, and we found that most of the experimental information can be satisfactorily reproduced.

\section{Reference}

[1] Staley, J. T., Liu, J., and Hunt Jr., W. T. 1997. “Alliages d'aluminium pour aérostructures.” Adv. Mater. Process 152: 17-24.

[2] Lathabai, S., and Lloyd, P. G. 2002. “The Effect of
Scandium on the Microstructure, Mechanical Properties and Weldability of a Cast Al-Mg Alloy.” Acta Mater. 50 (17): 4275-92.

[3] Huang, X., Pan, Q., Li, B., Liu, Z., Huang, Z., Yin, Z., 2014. "Effect of Minor Sc on Microstructure and Mechanical Properties of Al-Zn-Mg-Zr Alloy Metal-Inert Gas Welds.” J. Alloy. Compd. 629: 197-207.

[4] Palenzona, A., and Manfrinetti, P. 1997. "The Phase Diagram of the Sc-Au System.” J. Alloys Compd. 257 (1): 224-6.

[5] Kaufman, L., and Bernstein, H. 1970. Computer Calculation of Phase Diagrams. New York: Academic Press.

[6] Ansara, I. 1979. "Comparison of Methods for Thermodynamic Calculation of Phase Diagrams.” Int. Metals Rev. 24 (1): 20-53.

[7] Rider, P. E., Gschneidner Jr., K. A., and Mcmasters, O. D. 1965. "Gold Rich Rare Earth Gold Solid Solutions." Trans. Metall. Soc. AIME 233: 1488.

[8] Gschneidner Jr., K. A. 1990. "Physical Properties of the Rare Earth Metals.” Bull. Alloys Phase Diagr. 11 (3): 216-24.

[9] Massalski, T. B., ed. 1986. Binary Alloys Phase Diagrams. 1st ed. ASM International, 2178.

[10] Moffatt, W. G. 1988. The Handbook of Binary Phase 
Diagrams. Schenctady, NY: General Electric Commp.

[11] Okamoto, H., and Massalski, T. B., eds. Phase Diagrams of Binary Gold Alloys. ASM International, 261.

[12] Aldred, A. T. 1962. Intermediate Phases Involving Scandium. Trans. AIME 224: 1082-3.

[13] Reule, H., Steeb, S., and Donolato, C. 1971. "Structure of the Compounds $\mathrm{Ag}_{4} \mathrm{Sc}, \mathrm{Ag}_{2} \mathrm{Sc}, \mathrm{Au}_{4} \mathrm{Sc}, \mathrm{Au}_{2} \mathrm{Sc}$, and $\mathrm{Ag}_{3}$ Yb." J. Less Common Met. 24 (1): 108-12.

[14] Okamoto, H. 1998. “Al-Mg (Aluminum-Magnesium).” $J$. Phase Equilib. 19 (6): 599.

[15] Flahaut, J., and Thévet, F. 1980. "iliation structurale des composés de formule générale $\mathrm{AB}_{2}$ : Etude comparée des types $\mathrm{Co}_{2} \mathrm{Si}, \mathrm{Co}_{2} \mathrm{P}, \mathrm{PbCl}_{2}$, et SbSl." J. Solid State Chem. 32 (3): 365-76.

[16] Renouf, T. J. 1962. "A Comparison of the Structures $\mathrm{Zr}_{2} \mathrm{Al}_{3}$ and $\mathrm{ZrAl}_{2}$." Acta Crystallogr. 15 (3): 282-3.

[17] Saccone, A., Macciò, D., Giovannini, M., and Delfino, S. 1997. "The Praseodymium-Gold System." J. Alloys Comp 247: 134-40.

[18] Saccone, A., Macciò, D., Delfino, S., and Ferro, R. 1999. "The Neodymium-Gold Phase Diagram." Metall. Mater. Trans. A 30 (5): 1169-76.

[19] Podarevskaya, O. V., Kudin, V. G., and Sudavtsova, V. S. 2005. "Phase Diagram of the Scandium-Tin System." Powder Metall. Met. Ceram. 44: 463.

[20] Villars, P., and Calvert, L. D. 1985. Pearson's Handbook of Crystallogrphic Data for International, Phases. Metals Park, OH: ASM.

[21] Xu, K., Liu, S. H., Zhang, F., Du, Y., and Jin, Z. P. 2016. "Thermodynamic Calculations of the Au-Sc and Fe-Sc Systems." Calphad 54: 158-64.

[22] Fitzner, K., Jung, W. G., and Kleppa, O. J. 1991. "Thermochemistry of Binary Alloys of Transition Metals: The Me-Sc, Me-Y, and Me-La (Me = Ag, Au) Systems." Metall. Trans. A 22 (5): 1103-11.

[23] Meschel, S. V., and Kleppa, O. J. 2003. "Thermochemistry of Some Binary Alloys of Noble Metals $(\mathrm{Cu}, \mathrm{Ag}, \mathrm{Au})$ and Transition Metals by High Temperature Direct Synthesis Calorimetry." J. Alloys
Comp 350: 205-12.

[24] Kleppa, O. J., and Topor, L. 1985. "Thermochemistry of Binary Liquid Gold Alloys: The Systems $(\mathrm{Au}+\mathrm{Cr}),(\mathrm{Au}$ $+\mathrm{V}),(\mathrm{Au}+\mathrm{Ti})$, and $(\mathrm{Au}+\mathrm{Sc})$ at $1379 \mathrm{~K} . "$ Metall. Trans. A 16 (1): 93-9.

[25] Dinsdale, A. T. 1991. "SGTE Data for Pure Elements." Calphad-Computer Coupling of Phase Diagrams \& Thermochemistry 15: 317-425.

[26] Redlich, O., and Kister, A. T. 1948. "Algebraic Representation of Thermodynamic Properties and the Classification of Solutions." Ind. Eng. Chem. 40 (2): 345-8.

[27] Sundman, B., Jansson, B., and Andersson, J. O. 1985. "The Thermo-Calc Databank System." Calphad-Computer Coupling of Phase Diagrams \& Thermochemistry 9: 153-90.

[28] Jansson, B. 1984. "Computer Operated Methods for Equilibrium Calculations and Evaluation of Thermochemical Model Parameters." Ph.D. thesis, Royal Institute of Technology.

[29] Lupis, C. H. 1983. Chemical Thermodynamics of Metals North-Holland, NY: Prentice-Hall Inc.

[30] Chen, S. L., Daniel, S., Zhang, F., Chang, Y. A., Oates, W. A., and Schmid-Fetzer, R. 2001. "On the Calculation of Multicomponent Stable Phase Diagrams." $J$ Phase Equilib. 22: 373-8.

[31] Watanabe, S., and Kleppa, O. J. 1984. "Thermochemistry of Alloys of Transition Metals: Part IV. Alloys of Copper with Scandium, Yttrium, Lanthanum, and Lutetium." Metall. Trans. B 15 (2): 357-68.

[32] Bo, H., Liu, L. B., and Jin, Z. P. 2010. "Thermodynamic Analysis of Al-Sc, $\mathrm{Cu}-\mathrm{Sc}$ and $\mathrm{Al}-\mathrm{Cu}-\mathrm{Sc}$ System." $J$. Alloys Compd. 490 (1): 318-25.

[33] De Boer, F. R., Boom, R., Mattens, W. C. M., and Miedema, A. R. 1988. Trans. Met. Alloys, North-Holland, Amsterdam.

[34] Liu, X. J., Wang, S. L., and Wang, C. P. 2009. "Thermodynamic Assessments of the Sc-M (M: Ag, B and Th) Systems.” J. Alloys Compd 469 (1): 186-92. 